\title{
DEPRESSIVE SYMPTOMS AND PERCEPTION OF QUALITY OF LIFE IN PARKINSON'S DISEASE
}

\author{
Paula Scalzo, Arthur Kummer ${ }^{2}$, Francisco Cardoso ${ }^{3}$, Antonio Lucio Teixeira ${ }^{4}$
}

\begin{abstract}
Background: Depression has been proposed as a major contributor to poor quality of life (QoL) in Parkinson's disease (PD). Objective: To evaluate the relationship between depressive symptoms and QoL in subjects with PD. Method: Beck Depression Inventary (BDI) was used to evaluate depressive symptoms and Parkinson's Disease Quality of Life Questionnaire (PDQ-39) to assess the perception of the QoL. Results: Thirty seven patients (19 male/ 18 female) with a typical onset PD and mean disease duration of 7.7 years were studied. Higher scores on BDI correlated with poorer perception of the QoL. This association occurred at the expense of the following PDQ39 domains: mobility, activities of daily living, social support, cognition and emotional well-being dimensions. PD severity also correlated with QoL. Conclusion: Our study corroborates the assumption that depressive symptoms contributed significantly to QoL in PD.
\end{abstract}

KEY WORDS: Parkinson's disease, depression, quality of life.

\section{Sintomas depressivos e percepção da qualidade de vida na doença de Parkinson}

Resumo - Introdução: Depressão tem sido proposta como um importante fator para a piora da qualidade de vida (QV) na doença de Parkinson (DP). Objetivo: Avaliar a relação entre sintomas depressivos e a QV em indivíduos com DP. Método: Foi utilizado o Inventário de Depressão de Beck (IDB) para avaliar depressão e o Questionário de Qualidade de Vida na Doença de Parkinson (PDQ-39) para investigar a percepção da QV. Resultados: Trinta e sete pacientes (19 homens e 18 mulheres) com idade de início típica da DP e duração média da doença de 7,7 anos foram estudados. Maiores escores no IDB correlacionaram-se com pior percepção da QV. Essa associação ocorreu em virtude da pior percepção das dimensões de mobilidade, atividades da vida diária, apoio social, cognição e bem-estar emocional do PDQ-39. A gravidade da DP também se correlacionou com a QV. Conclusão: Nosso estudo corrobora o conceito de que os sintomas depressivos contribuem significativamente para a QV em indivíduos com DP.

PALAVRAS-CHAVE: Doença de Parkinson, depressão, qualidade de vida.

Parkinson's disease (PD) is a progressive neurodegenerative disease which affects $0.3 \%$ of the general population? PD is characterized by motor involuntary signs including bradykinesia, rigidity, resting tremor and postural instability. However, non-motor symptoms such as cognitive dysfunctions and psychiatric disorders are common ${ }^{2-4}$.

Depressive symptoms occur frequently, affecting nearly $50 \%$ of PD patients ${ }^{4-6}$. Depression has been recognized as a major contributor to poor quality of life (QoL), worse motor and cognitive functions, and caregiver burden in $\mathrm{PD}^{7}$. Several rating scales for screening and/or assessment of severity of depression are available and have been widely used to investigate depression in patients with $\mathrm{PD}^{7,8}$. The Beck Depression Inventory (BDI) is the most often used self-rating instrument for depressive symptoms in the clinical practice ${ }^{9}$. The BDI has been used in PD to screen depression, to measure its severity and to assess response to antidepressant treatment. Leentjens el al. evalu-

Neuropsychiatric Branch and Movement Disorders Clinic, Neurology Division University Hospital, Federal University of Minas Gerais (UFMG), Belo Horizonte MG, Brazil: 'Fisioterapeuta, Professora do Curso de Fisioterapia da Pontifícia Universidade Católica de Minas Gerais (PUC Minas, Betim) e da Faculdade Estácio de Sá, Belo Horizonte MG, Brazil; ${ }^{2}$ Psiquiatra; ${ }^{3}$ Neurologista, Professor do Departamento de Clínica Médica da Faculdade de Medicina da Universidade Federal de Minas Gerais, Belo Horizonte MG, Brazil; ${ }^{4}$ Neurologista e Psiquiatra, Professor do Departamento de Clínica Médica da Faculdade de Medicina da Universidade Federal de Minas Gerais, Belo Horizonte MG, Brazil. This work was partly funded by grants from Rede Instituto Brasileiro de Neurociência (IBN Net/Finep), Fundação de Amparo à Pesquisa do Estado de Minas Gerais (Fapemig) and Conselho Nacional de Desenvolvimento Científico e Tecnológico (CNPq).

Received 24 September 2008, received in final form 12 December 2008. Accepted 6 March 2009.

Dr. Antonio Lucio Teixeira - Departamento de Clínica Médica / Faculdade de Medicina da UFMG - Avenida Alfredo Balena 190 - 30130-100 Belo Horizonte MG - Brasil. E-mail: altexr@gmail.com 
ated the validity of the $\mathrm{BDI}$ as a screening and diagnostic instrument of depression in $\mathrm{PD}^{10}$. These authors proposed different cutoff scores for screening (8/9) and depression diagnosis $(16 / 17)^{10}$. Visser et al. confirmed that the BDI is a valid, reliable, and potential responsive instrument to assess the severity of depression in PD and suggested 14/15 as an optimal cutoff with acceptable sensitivity and specificity ". In a study with Brazilian PD patients, Silberman et al. demonstrated that maximum discrimination was obtained with a cutoff of $17 / 18^{7}$. Tumas et al. agreed that this cutoff score provided the optimal discrimination between depressed and non-depressed PD patients, whereas for diagnostic purposes the best cutoff score would be $26 / 27^{12}$.

There are specific instruments to assess motor function, stages of disease and impact in activities of daily living in PD. They are, respectively, the Unified Parkinson's Disease Rating Scale (UPDRS), the Hoehn-Yahr Scale $(\mathrm{HY})$ and the Schwab and England Activities of Daily Living Scale $(\mathrm{S} \& \mathrm{E})^{13,14}$. However, these scales do not assess the actual impact of the disease on the QoL of patients. There are different instruments to assess QoL in PD. The Parkinson's Disease Quality of Life Questionnaire (PDQ-39) is a well-validated, disease-specific questionnaire for PD and is one of the most used instruments ${ }^{15}$. A Brazilian version of PDQ-39 has been validated recently ${ }^{16}$.

The aim of this study was to evaluate the relationship between depressive symptoms, assessed by BDI, and different dimensions of QoL, assessed by PDQ-39, in subjects with PD.

\section{METHOD}

Demographic and clinical data were collected from $37 \mathrm{pa}-$ tients PD followed at the Movement Disorders Clinic, University Hospital of the Federal University of Minas Gerais (UFMG), Belo Horizonte, Brazil. The local ethics committee approval was obtained and all participants gave their informed consent prior to data collection.

The inclusion criteria were PD diagnosis and a cognitive functioning level to be capable to answer the questionnaires. The exclusion criteria were the presence of dementia, delirium, a comorbid neurological disease, and history of any previous neurosurgical procedure.

All participants underwent Mini-Mental Status Examination (MMSE), UPDRS, HY, S\&E, BDI and PDQ-39. MMSE was used to assess the general cognitive function and the recommended adaptations of its scoring method for the Brazilian elderly were considered ${ }^{17}$. UPDRS is currently the most widely accepted scale for measuring the different components of $\mathrm{PD}^{13}$. It has 3 subscales: UPDRS I - Mentation, Behavior, and Mood (range 0-16); UPDRS II - Activities of Daily Living (ADL) (range 0-52) and UPDRS III - Motor Examination (range 0-108). Each item is scored on a scale from 0 to 4 . A total of 176 points is possible, with 176 representing maximal (or total) disability and 0 representing no disability. The S\&E is widely used to assess disability in performing ADL for people with PD. It is a percentage scale divided into deciles, with $100 \%$ representing completely normal function and $0 \%$ representing total helplessness ${ }^{13}$. The HY classifies PD patients in five stages according to body distribution of symptoms and dependency. Patients in stage I are mildly affected, while in stage $V$ they are bedridden ${ }^{14}$.

The $\mathrm{BDI}$ is a self rating scale and is composed by 21 questions. Items 1 to 13 assess symptoms that are psychological in nature, while items 14 to 21 assess more somatic symptoms ${ }^{9}$. According to the Center of Cognitive Therapy, scores from 0 to 9 represent minimal depressive symptoms, scores of 10 to 16 indicate mild depression, scores of 17 to 29 indicate moderate depression, and scores of 30 to 63 indicate severe depression'. Nonetheless, BDI cutoff scores seem to depend on the characteristic of patients studied and the purpose of the instrument. As explained above, different cutoffs have been proposed for PD.

The PDQ-39 is a questionnaire with 39 items covering eight discrete dimensions: mobility (10 items), activities of daily living (6 items), emotional well-being ( 6 items), stigma (4 items), social support ( 3 items), cognition ( 4 items), communication ( 3 items), and bodily discomfort ( 3 items $)^{15}$. The score for each item ranges from zero (0) to four (4): "never"=0; "occasionally"=1; "sometimes"=2; "often" $=3$; "always" $=4$. Each dimension score ranges from 0 to 100 in a linear scale, in which zero is the best, i.e. no problem at all, and 100 is the worst, i.e. maximum level of problem.

For comparison of continuous variables, Student's t-test or the Mann-Whitney U-test were used in normally or non-nor-

Table 1. Demographic and clinical features of 37 patients with Parkinson's disease (PD).

\begin{tabular}{lc}
\hline Clinical parameters & $\mathrm{N}(\%)$ or mean \pm SD (range) \\
\hline Gender (male/female) & $19(51.3 \%) / 18(48.7 \%)$ \\
On levodopa therapy & $30(81.1 \%)$ \\
Age (years) & $65.0 \pm 7.9(51-84)$ \\
Age of PD onset (years) & $57.1 \pm 9.6(40-75)$ \\
Disease duration (years) & $7.7 \pm 4.7(1-15)$ \\
MMSE & $25.1 \pm 3.3(18-30)$ \\
UPDRS & $45.3 \pm 26.1(10-115)$ \\
UPDRS I & $2.8 \pm 2.2(0-10)$ \\
UPDRS II & $13.0 \pm 7.6(1-31)$ \\
UPDRS III & $29.8 \pm 19.0(4-75)$ \\
HY* & $2(1-4)$ \\
S\&E* & $80 \%(50-100 \%)$ \\
BDI & $16.4 \pm 10.6(0-46)$ \\
PDQ-39 & $21.7 \pm 18.0(1.9-65.1)$ \\
\hline
\end{tabular}

*Median (range). SD: standard deviation; MMSE: Mini-Mental State Examination; UPDRS: Unified Parkinson's Disease Rating Scale; HY: HoehnYahr Staging Scale; S\&E: Schwab and England Activities of Daily Living Scale; BDI: Beck Depression Inventory; PDQ-39: Parkinson's Disease Quality of Life Questionnaire. 
Table 2. Spearman's rank correlation coefficient $\left(r_{s}\right)$ and $p$-value between demographic and clinical variables, BDI and PDQ-39.

\begin{tabular}{lccccc}
\hline & \multicolumn{2}{c}{ BDI } & & \multicolumn{2}{c}{ PDQ-39 } \\
\cline { 2 - 3 } \cline { 5 - 6 } Variables & Coefficient of correlation & $\mathrm{p}$-Value & & Coefficient of correlation & $\mathrm{p}$-Value \\
\hline Age & -0.127 & 0.454 & & -0.369 & 0.025 \\
Age of PD onset & -0.170 & 0.315 & 0.332 & -0.390 & 0.017 \\
Disease duration & 0.164 & 0.535 & 0.001 & 0.255 & 0.128 \\
UPDRS I & 0.504 & 0.001 & 0.641 & $<0.001$ \\
UPDRS II & 0.318 & 0.055 & 0.757 & $<0.001$ \\
UPDRS III & 0.447 & 0.006 & 0.619 & $<0.001$ \\
UPDRS Total & 0.274 & 0.101 & 0.719 & $<0.001$ \\
HY & -0.421 & 0.009 & 0.519 & $<0.001$ \\
S\&E & -0.190 & 0.261 & -0.742 & $<0.001$ \\
MMSE & 1 & & -0.052 & 0.760 \\
BDI & 0.608 & $<0.001$ & 0.608 & $<0.001$ \\
PDQ-39 & & & 1 & \\
\hline
\end{tabular}

UPDRS: Unified Parkinson's Disease Rating Scale; HY: Modified Hoehn-Yahr Staging Scale; S\&E: Schwab and England Activities of Daily Living Scale; BDI: Beck Depression Inventory; PDQ-39: Parkinson's Disease Quality of Life Questionnaire.

Table 3. Coefficient of correlation of Spearman $\left(r_{s}\right)$ and p-value between BDI score and PDQ-39 dimensions, and classification of Munro for the magnitude of the correlations ${ }^{18}$.

\begin{tabular}{lccc}
\hline Dimensions & $\mathrm{r}_{\mathrm{s}}$ & $\mathrm{p}$-Value & Classification \\
\hline Mobility & 0.437 & 0.007 & Low \\
Activities of daily living & 0.460 & 0.004 & Low \\
Emotional well-being & 0.513 & 0.001 & Moderate \\
Stigma & -0.007 & 0.968 & No correlation \\
Social support & 0.392 & 0.016 & Low \\
Cognition & 0.402 & 0.014 & Low \\
Communication & 0.148 & 0.382 & No correlation \\
Bodily discomfort & 0.279 & 0.095 & No correlation \\
\hline
\end{tabular}

mally distributed data, respectively. Comparisons of categorical data were performed by using the $\chi^{2}$ test. Correlation analyses between scales were calculated using Pearson's correlation or Spearman's rank correlation coefficient in normally or nonnormally distributed data, respectively. The magnitude of correlation was classified according to Munro (low $=0.26-0.49$; moderate $=0.50-0.69$; high $=0.70-0.89$; very high $=0.90-1.00$ ) for interpretation of the correlation coefficients ${ }^{18}$. Statistical significance was set at $p<0.05$. SPSS v15.0 software was used for statistical analyses.

\section{RESULTS}

Our sample was composed mainly by elderly patients with a typical-onset PD (i.e. onset after age 50) (Table 1). Gender proportion was well-distributed. Severity of PD symptoms according to UPDRS scores was moderate in most participants. The median $\mathrm{HY}$ disease staging was 2 , compatible with mild-to-moderate disease. The median
S\&E was $80 \%$ suggesting that most patients were functionally independent.

Patients with more severe depressive symptoms had a worse QoL (Table 2). Higher scores on BDI correlated with a more severe disease as assessed by UPDRS, especially its subscales I (Mentation, Behavior, and Mood) and II (ADL). BDI also correlated with S\&E. BDI did not correlate with the subscale 3 of the UPDRS and HY.

QoL correlated with the severity of PD as assessed by different instruments, including UDPRS (total score and its 3 subscales), HY and S\&E (Table 2). Interestingly, younger patients and patients with an earlier onset of PD had a worse QoL (Table 2).

When evaluating specifically the correlation between BDI and PDQ-39 dimensions, there was low to moderate correlation with mobility, activities of daily living, social support, cognition and emotional well-being dimensions. 
Table 4. Demographic and clinical features of patients with Parkinson's disease (PD) compared groups of the BDI (score $\leq 17$ or $\geq 18$ ).

\begin{tabular}{lccc}
\hline & BDI $\leq 17$ & BDI $\geq 18$ & p-Value \\
\hline Number of patients & $\mathrm{N}(\%)$ & $\mathrm{N}(\%)$ & \\
On levodopa therapy & $23(62.7 \%)$ & $14(37.8 \%)$ & \\
Male/Female & $17(45.9 \%)$ & $13(35.1 \%)$ & 0.587 \\
& $14 / 9$ & $5 / 9$ & 0.145 \\
Age (years) & Mean (SD) & Mean (SD) & \\
Disease duration (years) & $65.8(8.1)$ & $63.6(7.7)$ & 0.424 \\
Age of PD onset (years) & $6.9(4.3)$ & $8.9(5.1)$ & 0.217 \\
MMSE & $58.7(9.5)$ & $54.5(9.5)$ & 0.197 \\
HY & $25.6(2.8)$ & $24.3(3.9)$ & 0.269 \\
S\&E & $2.0(0.7)$ & $2.57(0.8)$ & 0.052 \\
& $83.5(10.3)$ & $75.0(12.8)$ & 0.034 \\
UPDRS & Median (range) & Median (range) & \\
UPDRS I & $30.0(10-106)$ & $59.0(15.0-115.0)$ & 0.020 \\
UPDRS II & $2.0(0-5.0)$ & $3.0(0-10.0)$ & 0.012 \\
UPDRS III & $9.0(1-26.0)$ & $17.5(4.0-31.0)$ & 0.008 \\
PDQ-39 & $21.0(4.0-75.0)$ & $41.5(7.0-74.0)$ & 0.093 \\
\hline
\end{tabular}

MMSE: Mini-Mental State Examination; UPDRS: Unified Parkinson's Disease Rating Scale; HY: Hoehn-Yahr Staging Scale; S\&E: Schwab and England Activities of Daily Living Scale; BDI: Beck Depression Inventory; PDQ-39: Parkinson's Disease Quality of Life Questionnaire.

Table 5. Comparison of PDQ-39 dimensions between PD patients who scored $\leq 17$ on $B D I$ and who scored $\geq 18$ on $B D I$.

\begin{tabular}{lccc}
\hline Dimension & BDI $\leq 17$ & BDI $\geq 18$ & p-Value \\
\hline & Median (range) & Median (range) & \\
Mobility & $0(0-90)$ & $26.2(0-90)$ & 0.012 \\
Activities of daily living & $12.5(0-100)$ & $52.1(0-91.7)$ & 0.017 \\
Emotional well-being & $8.3(0-45.8)$ & $33.3(0-91.6)$ & 0.013 \\
Stigma & $0(0-75)$ & $0(0-62.5)$ & 0.439 \\
Social support & $0(0-33.3)$ & $0(0-62.5)$ & 0.030 \\
Cognition & $18.7(0-56.2)$ & $37.5(0-68.7)$ & 0.007 \\
Communication & $0(0-83.3)$ & $8.3(0-66.6)$ & 0.467 \\
Bodily discomfort & $25.0(0-66.6)$ & $50.0(0-91.6)$ & 0.034 \\
Total score & $10.3(1.9-65.1)$ & $30.2(6.4-63.8)$ & 0.001 \\
\hline
\end{tabular}

BDI: Beck Depression Inventory.

For the remaining three dimensions, there was no correlation (Table 3).

According to Silberman et al. ${ }^{7}$ and Tumas et al..$^{2}$, the cutoff score of $17 / 18$ provided optimal discrimination between depressed and non-depressed Brazilian patients with PD. Patients were divided into two groups according to their score on the BDI. Twenty two patients (59.5\%) presented scores between 0 to 17 and fifteen patients (40.5\%) equal to or above 18 . There were no significant differences between these two groups regarding gender, age, disease duration and MMSE. However, the group with higher values on the BDI $(\geq 18)$ had significantly higher scores in UPDRS and its subscales I (Mentation, Behavior, and Mood) and II (ADL), more advanced stages in HY, lower level of functional independence in S\&E, and worse perception of QoL in PDQ-39 (Table 4). Regarding PDQ-39 domains, there were significant differences in the dimensions mobility, activities of daily living, emotional well-being, so- 
cial support, cognition and bodily discomfort when comparing patients with and without depression according to BDI (Table 5).

\section{DISCUSSION}

Previous studies pointed out the close association between depression and poor QoL ${ }^{19-21}$. Our study also found a correlation between higher scores in BDI and a worse perception of the QoL. This association was sustained mainly by the worst perception of the mobility, activities of daily living, social support, cognition and emotional well-being dimensions of PDQ-39. In a categorical analysis, it was also observed that the group of patients with more depressive symptoms (BDI $\geq 18$ points) showed statistically significant higher scores in PDQ-39, sustained by the coincident dimensions of mobility, activities of daily living, emotional well-being, social support and cognition.

It must be taken into consideration that PDQ-39 is a patient questionnaire, and thus it has a strong subjective influence. Moreover, some PDQ-39 dimensions overlap with depressive symptoms. For instance, the mobility dimension argues whether the patient has difficulty doing leisure activities which he/she would like to do. This affirmative may be mistaken as abulia or anhedonia that are depressive symptoms. The bodily discomfort dimension assesses mainly pain complaints which are also frequent in depressive elderly. The questions of the social support dimension cover mainly subjective feelings of helplessness. The cognitive domain asks about symptoms such as daily somnolence, lack of concentration and memory problems. The well-being dimension, which correlated more strongly with $\mathrm{BDI}$, is probably the domain with more specific depressive and anxiety symptoms.

Depressive PD patients can overestimate their motor impairment. Interestingly, BDI did not correlate with instruments which objectively assessed motor and cognitive functioning, such as the subscale III of UPDRS, HY and MMSE. In line with these findings, other studies have found no significant correlation between individual motor features of PD and frequency and/or severity of depression in $\mathrm{PD}^{12}$. On the other hand, BDI correlated with the subscales I (Mentation, Behavior, and Mood) and II (ADL) of UPDRS and with S\&E. It should be mentioned that the section I of UPDRS has been even proposed as an adequate screen for depression ${ }^{22}$.

This study also found that younger patients and an earlier onset of PD related with worse perception of the QoL. Such association may not be accounted only by depressive symptoms, as frequency of psychiatric disorders in young-onset PD does not differ from typical-onset $\mathrm{PD}^{4}$. Alternatively, Schrag et al. demonstrated that patients with a younger onset of disease experience more frequently loss of employment, marital problems, and greater perceived stigmatization than do older-onset patients with PD 23 .

Our study showed that higher scores in all sub-scales of UPDRS and total UPDRS, advanced stages of disease when assessed by HY stages and worst level of functional independence evidenced by the S\&E affected negatively the perception of the QoL by PD patient. Indeed QoL of patients with a chronic disease like PD is influenced by the patient's symptoms and physical functioning as well as psychosocial variables. For instance, with PD progression, significant changes in posture and predisposition to fall develop. This predisposition to fall may induce psychological reaction characterized by fear of future falling $^{24}$. This fear of falling can be maladaptive when it compels patients to restrict their mobility, independence and social participation, leading to further functional decline and poorer $\mathrm{QoL}^{19,24}$. The limitation and gradual physical disabilities in performance are important factors in worsening QoL of PD patients.

Some limitations of our study must be highlighted. Our study involved a small sample of PD patients. This sample was mainly composed by PD patients with a mild to moderate disease. Just few patients were rated 3 and 4 in HY stages. The majority of patients studied presented low scores in BDI. We did not have a control group of depressed patients in order to compare the results of both depressed and non-depressed PD patients. Notwithstanding, our data were in line with previous reports in the literature ${ }^{20,25}$.

Depression in PD has been pointed out as the main predictor of worse QoL ${ }^{19,21}$. Our study corroborates the concept that depressive symptoms are associated with a worse QoL. However, depression is rarely reported by PD patients to their clinicians, and it may not be even recognized by the own patients ${ }^{26}$. According to the Global Parkinson's Disease Survey Steering Committee, only $1 \%$ of patients report depression as a concomitant problem, although $50 \%$ of them were considered depressed ${ }^{26}$. Thus, clinicians must be encouraged to investigate depressive symptoms in patients with PD as their treatment is crucial to improve QoL.

\section{REFERENCES}

1. Lau LM, Breteler MM. Epidemiology of Parkinson's disease. Lancet Neurol 2006;5:525-535.

2. Calne D. A definition of Parkinson's disease. Parkinsonism Relat Disord 2005;11(Suppl):S39-S40.

3. Samii A, Nutt JG, Ransom BR. Parkinson's disease. Lancet 2004;29:1783-1793.

4. Kummer A, Cardoso C, Teixeira AL. Frequency of psychiatric disorders in young-onset Parkinson's disease does not differ from typical-onset Parkinson's disease. Parkinsonism Relat Disord 2009;15:153-155. 
5. Zesiewicz TA, Gold M, Chari G, Hauser RA. Current issues in depression in Parkinson's disease. Am J Geriatr Psychiatry 1999;7:110-118.

6. Okun MS, Watts RL. Depression associated with Parkinson's disease. Clinical features and treatment. Neurology 2002;58:S63-S70

7. Silberman CD, Laks J, Capitão CF. Recognizing depression in patients with Parkinson's disease: accuracy and specificity of two depression rating scale. Arq Neuropsiquiatr 2006;64:407-411.

8. Stebbins GT, Goetz CG. Depression rating scales in Parkinson's disease: critique and recommendations. Mov Disord 2007;22:1077-1092.

9. Gorenstein C, Andrade L. Inventário de Depressão de Beck: propriedades psicométricas da versão em português. Rev Psiquiatr Clín 1998;25:245-250.

10. Leentjens AF, Verhey FRJ, Luijckz GJ, Troost J. The validity of the Beck Depression Inventory as a screening and diagnostic instrument for depression in patients with Parkinson's disease. Mov Disord 2000;15:1221-1224.

11. Visser M, Leentjens AF, Marinus J, Stiggelbout AM, van Hilten JJ. Reliability and validity of the Beck depression inventory in patients with Parkinson's disease. Mov Disord 2006;21:668-672.

12. Tumas V, Rodrigues GGR, Farias TLA, Crippa JAS. The accuracy of diagnosis of major depression in patients with Parkinson's disease: a comparative study among the UPDRS, the Geriatric Depression Scale and the Beck Depression Inventory. Arq Neuropsiquiatr 2008;66:152-156.

13. Fahn S, Elton R. Unified Parkinson's Disease Rating Scale. In: Fahn S, Marsden CD, Caine DB, Goldstein M, editors. Recent developments in Parkinson's disease. Vol 2. Florham Park: Macmillan Health Care Information, 1987:153-63, 293-304.

14. Hoehn MM, Yahr MD. Parkinsonism: onset, progression and mortality. Neurology 1967;17:427-442.

15. Peto V, Jenkinson C, Fitzpatrick R. PDQ-39: a review of the development, validation and application of a Parkinson's dis- ease quality of life questionnaire and its associated measures. J Neurol 1998;245(Suppl):S10-S14.

16. Carod-Artal FJ, Martinez-Martin P, Vargas AP. Independent validation of SCOPA-psychosocial and metric properties of the PDQ-39 Brazilian version. Mov Disord 2007;22:91-98.

17. Brucki SMD, Nitrini R, Caramelli P, Bertolucci PHF, Okamoto IH. Sugestões para o uso do Mini-Exame do Estado Mental no Brasil. Arq Neuropsiquiatr 2003;61:777-781.

18. Munro BH. Statistical methods for health care research. $4^{\text {th }}$ Ed. Philadelphia: Lippincott/Raven Publishers, 2001:223-243.

19. Schrag A, Jahanshahi M, Quinn N. What contributes to quality of life in patients with Parkinson's disease. J Neurol Neurosurg Psychiatry 2000;69:308-312.

20. Behari M, Srivastava AK, Pandey RM. Quality of life in patients with Parkinson's disease. Parkinsonism Relat Disord 2005;11:221-226

21. Kuopio AM, Marttila RJ, Helenius H, Toivonen M, Rinne UK. The quality of life in Parkinson's disease. Mov Disord 2000;15:216-223.

22. Starkstein SE, Merello M. The Unified Parkinson's Disease Rating Scale: validation study of the mentation, behavior, and mood section. Mov Disord 2007;22:2156-2161.

23. Schrag A, Hovris A, Morley D, Quinn N, Jahanshahi M. Youngversus older-onset Parkinson's disease: impact of disease and psychosocial consequences. Mov Disord 2003;18:1250-1256.

24. Franchignoni F, Martignoni E, Ferriero G, Pasetti C. Balance and fear of falling in Parkinson's disease. Parkinsonism Relat Disord 2005;11:427-433.

25. Souza RG, Borges V, de Azevedo Silva SMC, Ferraz HB. Quality of life scale in Parkinson's disease PDQ-39 - (Brazilian Portuguese version) to assess patients with and without levodopa motor fluctuation. Arq Neuropsiquiatr 2007;65:787-791.

26. Global Parkinson's Disease Survey Steering Committee. Factors impacting on quality of life in Parkinson's disease: results from an international survey. Mov Disord 2002;17:60-67. 